A summary of new products and services for materials research..

Handheld Long-Wave UV Radiometer: The DM-365X from Spectroline ${ }^{\circledR}$ measures long-wave UV $(320-400 \mathrm{~nm})$ with accuracy of better than $\pm 5 \%$, traceable to NIST standards over its measurement range of $0-19,990 \mu \mathrm{W} / \mathrm{cm}^{2}$. The autozeroing feature eliminates the need for zero adjustment during calibration or use. The meter is calibrated by pyroelectric methods for maximum precision, with good linearity and cosine response. An interference filter controls spectral coverage, and only one intensity reading is necessary to obtain true values.

Circle No. 64 on Reader Service Card.

Temperature-Sensing Analytical Balance: The Alliance/OHAUS ${ }^{\circledR}$ Explorer $^{\mathrm{TM}}$ from Alliance Scale features an internal calibration system that senses changes in ambient temperature and indicates when to calibrate. Users can select weighing modes, stability levels, and filters and then read the results on an LCD display. Weighing modes include grams, milligrams, and ounces, and an audit trail can be generated for ISO-9000 requirements. Features include auto-zero tracking, RS232 bidirectional interface, spill gutter, and removable draft shields.

Circle No. 72 on Reader Service Card.

Rotary Vane Vacuum Pumps: PreVac's lubricated RV vacuum pumps feature $25 \%$ fewer moving parts than competitive pumps for reduced downtime and easier maintenance. The series includes nine lubricated RV pumps in two models: the PH series for vacuum applications down to 0.5 torr, and the PR series down to 10 torr. Both offer a performance range of $4-185 \mathrm{ft}^{3} / \mathrm{min}$ and horsepower range of $0.5-10 \mathrm{HP}$. Pump motors are direct drive $1750 \mathrm{RPM}$, available in single- or three-phase versions. A cooling shroud is included, which lowers operating temperatures.

Circle No. 61 on Reader Service Card.

Digital Pulse Generator: Merchantek Electro-Optics' Model 9318 is an eightchannel, eight-output digital pulse generator for end-use and OEM applications such as control and testing of YAG and excimer lasers and high-speed motion and stop-action imaging. The microprocessor-controlled unit can synchronize up to eight instruments simultaneously. An extended feature provides divide-by- $n$ function for four channels, enabling the instrument to generate pulses at a submultiple of the fundamental frequency. Users can select the delay and pulsewidth for each channel from $1 \mu \mathrm{s}$ to $99 \mathrm{~s}$.

Circle No. 69 on Reader Service Card.

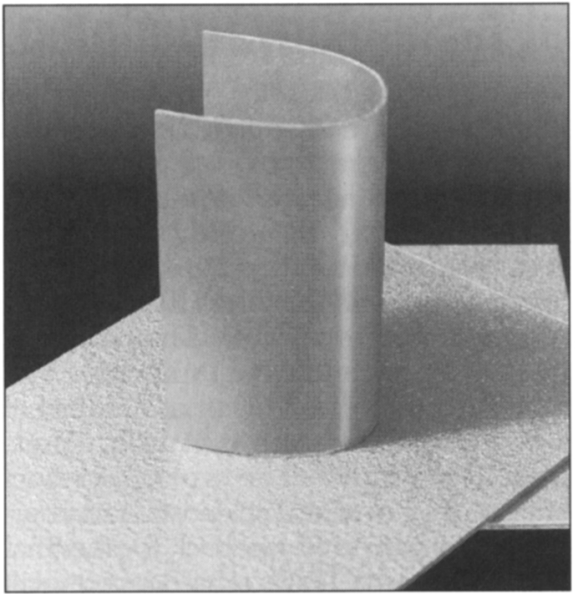

Flexible Magnetic Composite Sheet

Tokin's RF Series Flex-Suppressor suppresses quasi-microwave band radiation noise $(100 \mathrm{MHz}-1.5 \mathrm{GHz})$ inside frequency electric equipment by shielding and absorbing the noise. It eliminates crosstalk between PC boards and reduces the reflection of radiation noise inside an enclosed case. The material is available in thicknesses of $0.3-2 \mathrm{~mm}$ and in singleand double-sided absorbing sheets. It can be cut, machine applied, glued, or wrapped over components such as highspeed ICs and LSIs.

Circle No. 74 on Reader Service Card.

Diffuse Coating Service: Labsphere's Optoblack ${ }^{\mathrm{TM}}$ Diffuse Coating is designed for use over the $0.25-16 \mu \mathrm{m}$ wavelength region. The coating displays high lambertian characteristics and light absorption properties necessary for stray light control, thermal control, visual target cues, and calibration. The water-based sprayed-on coating can be applied to rigid plastic and metal substrates. The reflectance coating service is available for single component or multiple OEM requirements.

Circle No. 60 on Reader Service Card.

Flip Chip Placement System and Bonder: Semiconductor Equipment's Model850 manual flip chip placement system is capable of placement accuracies within $\pm 12 \mu \mathrm{m}$. The device uses a cube beam splitter to simultaneously present the flip chip and substrate, plus a video camera and monitor for alignment and placement. The Model 410 flip chip bonder offers $\pm 5 \mu \mathrm{m}$ precision and fast-cycle bonding via spot heating with hot gas, high-intensity light beam, or infrared laser. An optional ultrasonic scrub is available for thermosonically bonding microwave flip chip die. Both models may be used for polymer adhesive and solder reflow applications.

Circle No. 62 on Reader Service Card.
200-Watt Modular X-Ray Power Supplies: Series XMA power supplies from Universal Voltronics are designed for applications requiring stable, low-ripple voltages up to $60 \mathrm{kV}$, with a $30 \mathrm{kHz}$ filament voltage output of 3-12 volts. Available in 16 models, the units offer flexible control via a 25-pin I/O connector that permits analog control of tube and filament voltage, remote cathode voltage, emission current, and filament current monitoring, and filament idle.

Circle No. 63 on Reader Service Card.

Scanning Probe Microscope System: TopoMetrix Accurex II $^{\mathrm{TM}}$ SPM provides high-resolution surface measurements for industrial and research applications. Patented TrueMetrix ${ }^{\mathrm{TM}}$ closed-loop, linearized scanners provide accurate measurements regardless of scan size or orientation. Zooming from large scans $(100 \mu \mathrm{m})$ to selected features is done in a single step. The system is capable of a wide range of operating modes, including AFM (contact, near contact, and noncontact), MFM, LFM, EFM, SEPM, SThM, and lithography.

Circle No. 66 on Reader Service Card.

\section{Carbon Dioxide Laser Power} Supply: Universal Voltronics' BCO2 high-voltage power supplies offer superpulse capabilities, with maximum pulse currents to $60 \mathrm{~mA}$ and repetition rates to $5 \mathrm{kHz}$. Available at 300- or 700-watt power levels, the products offer full power to $75 \%$ of maximum voltage. A switching design operating at $42 \mathrm{kHz}$ provides efficiency and low heat generation. The power supplies are optimized for use in mid-power $\mathrm{CO}_{2}$-laser applications.

Circle No. 73 on Reader Service Card.

Integrated Turbomolecular Vacuum Pumping System: Varian's Turbo-V141 Navigator combines the pump, electronics, and cooling fan in one unit. The volume of the "plug and pump" system is $50 \%$ less than that required by an equivalent conventional solution, and only one connection point is needed, facilitating integration and reducing installation costs. Users plug in the system, and it begins to pump. An LED indicates the operating condition, and a frequency setpoint and digital I/O are available. Circle No. 67 on Reader Service Card.

Circulators: Free 16-page brochure from Fisher Scientific features NESLAB Instruments circulators for lab applications. Products include constant-temperature refrigerated, low-temperature, heating, and specialty circulators; water baths; immersion coolers; and recirculating chillers. Circle No. 65 on Reader Service Card. 